\title{
Anatomical evaluation of nasopalatine canal on cone beam computed tomography images
}

\author{
i. Bahşi1 ${ }^{1}$ M. Orhan ${ }^{1}$, P. Kervancioğlu1, E.D. Yalçin², A.M. Aktan³ \\ ${ }^{1}$ Department of Anatomy, Faculty of Medicine, Gaziantep University, Gaziantep, Turkey \\ 2Department of Dentomaxillofacial Radiology, Faculty of Dentistry, Gaziantep University, Gaziantep, Turkey \\ ${ }^{3} D D S$, PhD, Gaziantep, Turkey
}

[Received: 29 April 2018; Accepted: 25 June 2018]

Background: Nasopalatine canal (NPC) (incisive canal) morphology is important for oral surgery techniques carried out on the maxilla, in the treatment of nasopalatine cyst, palatal pathologies that require a surgical intervention.

Materials and methods: The morphology of NPC was classified in sagittal, coronal and axial planes on the cone beam computed tomography (CBCT). The length of NPC was found by measuring the distance between the mid-points of nasopalatine foramen and incisive foramen. The numbers, shapes and diameters of incisive and nasopalatine foramina were examined. Nasopalatine angle present between the NPC and the palate and anterior to the NPC was measured.

Results: In the sagittal plane, the shape of NPC was classified in six groups: $26.7 \%$ hourglass, $14.7 \%$ cone, $13.3 \%$ funnel, $16.0 \%$ banana, $28.7 \%$ cylindrical and $0.7 \%$ reverse-cone-shaped. In the coronal plane, shape of NPC was classified in three groups: $63.3 \%$ Y-shaped, 36.0\% single canal, 0.7\% double canal and external border of NPC was classified in four groups: $26.7 \% \mathrm{U}, 28.7 \% \mathrm{Y}, 44.0 \% \mathrm{~V}$ and $0.7 \%$ reverse- $V$-shaped. In the axial plane, the shape of nasopalatine foramen, incisive foramen and NPC at the mid-level was evaluated. The shape of the canal was detected as four types at three evaluated levels: round, oval, heart- and triangle-shaped. It was seen in every three axial planes that the round group is more than the others.

Conclusions: The morphological properties and variations of NPC should be considered with a correct radiological evaluation so as to prevent the complications and improper practices in local anaesthesia, maxillary surgery and implant surgery practices. Especially dentists, otolaryngologist and plastic surgeons need to know the anatomy and variations of NPC. (Folia Morphol 2019; 78, 1: 153-162)

Key words: cone beam computed tomography, nasopalatine canal, nasopalatine foramen, incisive foramen

\section{INTRODUCTION}

Nasopalatine canal (NPC) (incisive canal) is situated between both maxillae, posterior to the central incisor teeth and in the midline of the palate at the maxillary area. It is a canal located between nasal and oral cavity $[8,34]$. There is confusion in naming the superior and inferior openings of the NPC in the literature [6]. Inferior opening of NPC is named incisive foramen or foramina of Stenson [6, 15, 34]. Although superior opening of NPC is not named in the Terminologia Anatomica [15], it is named as nasopalatine foramen in the literature $[6,8,28,32,33]$. Nasopalatine nerve, the terminal branches of greater palatine artery, fat and small salivary glands, and

Address for correspondence: i. Bahşi, Department of Anatomy, Faculty of Medicine, Gaziantep University, Gaziantep, Turkey, tel: +903423606060/74070, fax: +90342 47207 18, e-mail: dr.ilhanbahsi@gmail.com 
fibrous connective tissue are situated in this canal $[16,29,34]$.

Nasopalatine canal morphology is very important in the planning of oral surgery techniques carried out on the maxillae, in the treatment of nasopalatine cyst, palatal pathologies that require a surgical intervention $[5,11,29,31]$. Successful dental implants in the anterior maxilla are detected by the available bone and neighbouring neurovascular structures [24]. It is also possible to place an implant into the NPC at the time of surgery [10]. Moreover, due to higher aesthetic expectations for anterior maxillary region recently, the need for radiological recognition of anatomical structures also increased [13].

The aim of the present study is to examine the NPC morphology on cone beam computed tomography (CBCT) images of the individuals.

\section{MATERIALS AND METHODS}

A total of 150 CBCT images with no pathology of 75 female and 75 male subjects aged 18-65 years were selected randomly. The images of patients who were admitted to Gaziantep University Faculty of Dentistry for any reason were evaluated retrospectively by Planmeca Romexis (Planmeca, Helsinki, Finland) programme. The study was approved by the Clinical Trials Ethics Committee, within which the work was undertaken. Incomplete, inconsistent or confusing information about any variable; artefact images that would prevent the detection and measurement of reference points; the $\mathrm{CBCT}$ images of the cases with NPC cyst, which might seriously affect the alveolar bone and nasopalatine canal dimensions, or with metabolic, developmental or inflammatory source jaw diseases were not included into the study. The morphology of NPC was classified in sagittal, coronal and axial planes (Figs. 1-5). The length of NPC was found by measuring the distance between the midpoints of nasopalatine foramen and incisive foramen. The diameters of nasopalatine foramen and incisive foramen were examined (Fig. 6). The shape and numbers of nasopalatine foramen, incisive foramen and NPC at the mid-level were evaluated (Figs. 4, 5). The nasopalatine angle located anteriorly between the axis of NPC and the palate was measured (Fig. 6).

\section{Compliance with ethical standards}

This study was approved by the ethics committee of Gaziantep University (approval date and number: 07 March 2016; 2016/72). We declare that this hu- man study has been approved by the ethics committee of Gaziantep University and has, therefore, been performed in accordance with the ethical standards laid down in the Declaration of Helsinki and its later amendments.

\section{Statistical analysis}

The data were evaluated statistically. The suitability of numeric data for normal distribution was tested by using the Shaphiro-Wilk test. Student t test was used in the comparison of the variables suitable for the normal distribution in two groups; ANOVA test was used in the comparison of them in three or more groups. The relations between numeric variables were tested by using the Pearson correlation coefficient and the relations between categorical variables were tested by using the $\chi^{2}$ test. The SPSS 22.0 software package was used in the analyses. $\mathrm{P}<0.05$ was accepted statistically significant.

\section{RESULTS}

Nasopalatine canal was examined in detail on the CBCT images of 75 female (mean age: 41.19 years) and 75 male (mean age: 41.20 years) cases between the ages of 18 and 65 years. No significant mean age difference existed between the genders ( $p>0.495)$.

\section{The shape of NPC}

In the sagittal plane, the shape of NPC was classified in six groups: hourglass, cone, funnel, banana, cylindrical and reverse cone-shaped (Table 1, Fig. 1). In the coronal plane, the shape of NPC (Fig. 2) was classified in three groups: Y-shaped, single canal and double canal and external border of NPC (Fig. 3) was classified in four groups: U, Y, V and reverse V-shaped (Table 1). In the axial plane, the shape of nasopalatine foramen, incisive foramen and NPC at the mid-level was detected as four types: round, oval, heart- and triangle-shaped (Table 1, Fig. 4).

Typologies that were detected only in 1 case (reverse cone, reverse $V$ and triangle-shaped) were not evaluated during the correlation and comparison in order not to affect the statistical significance.

The shape of NPC was compared with age and gender in three planes. It was seen in the sagittal and coronal planes that there were not a significant relationship between the shape of NPC and the gender ( $p=0.762, p=0.820, p=0.836$, respectively) and age $(p=0.998, p=0.890, p=0.919$, respectively). In the axial plane, the shape of nasopalatine foramen, 

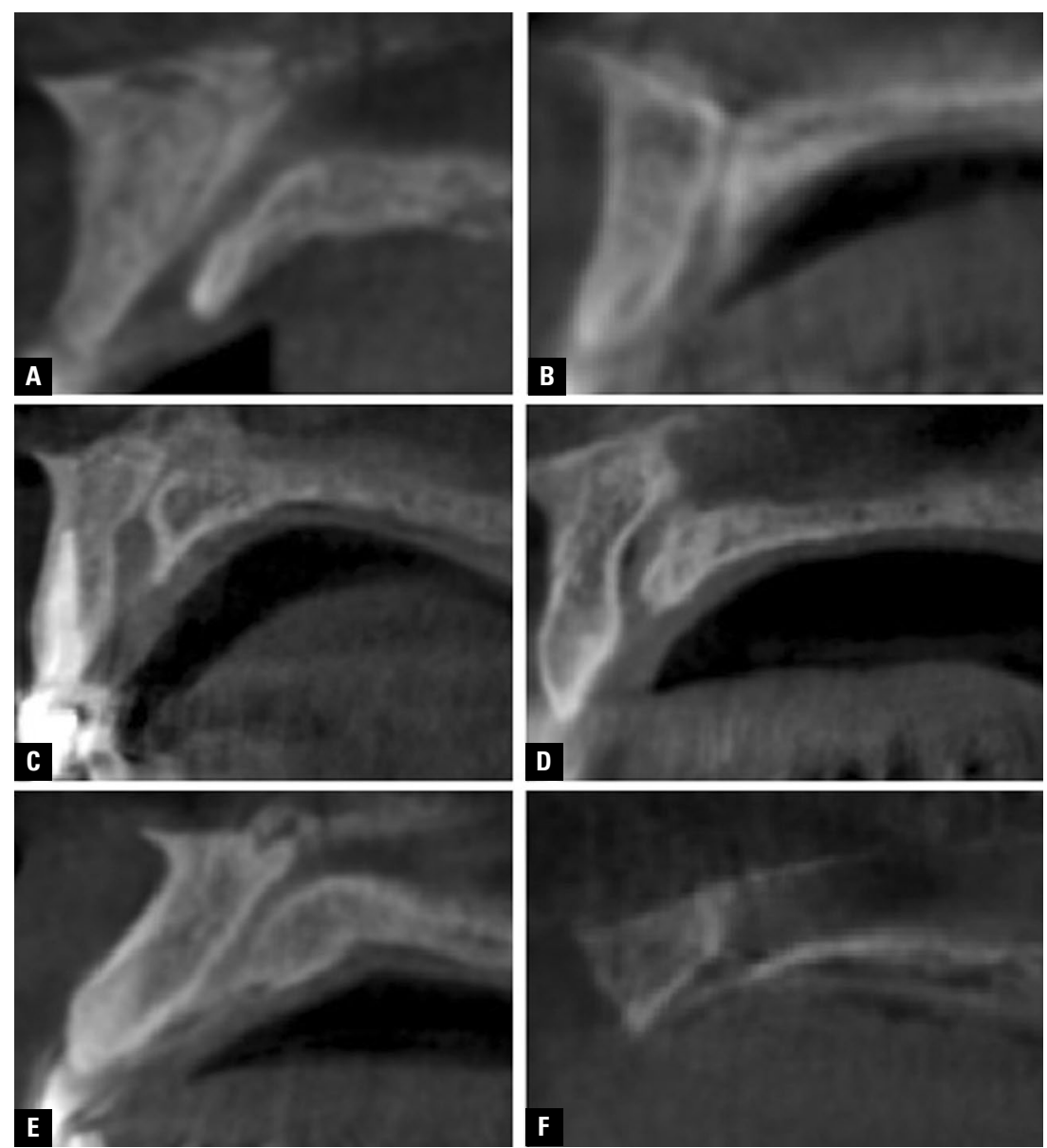

Figure 1. The morphology of nasopalatine canal was classified in sagittal plane; A. Hourglass-shaped; B. Cone-shaped; C. Funnel-shaped; D. Banana-shaped; E. Cylindrical; F. Revers cone-shaped.
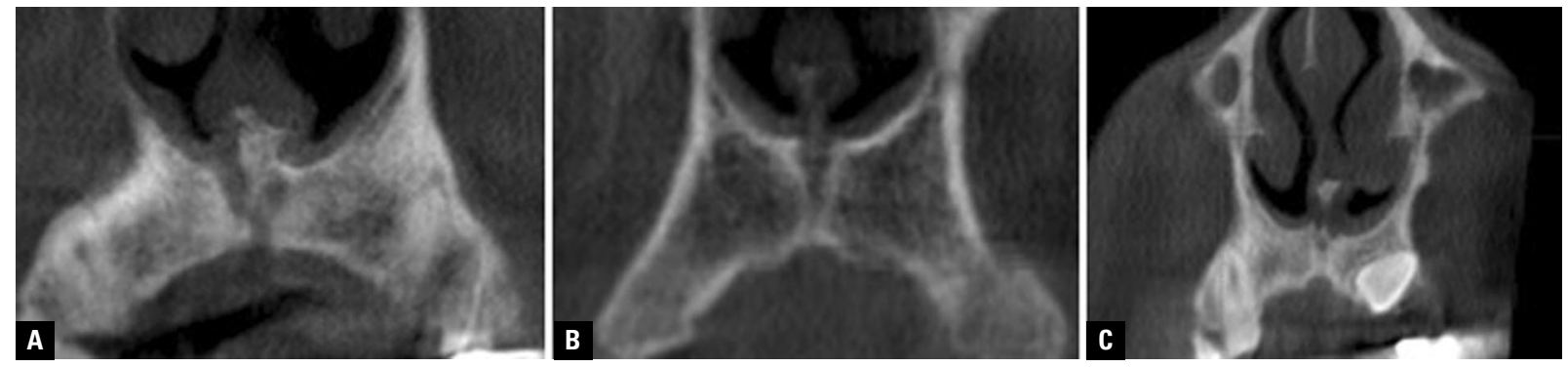

Figure 2. The shape of nasopalatine canal was classified in coronal plane; A. Y-shaped; B. Single canal; C. Double canal.

incisive foramen and NPC at the mid-level were compared with age and gender. With respect to gender, there was not a significant relationship at the mid-level of NPC and incisive foramen $(p=0.455, p=0.162$, respectively), but there was a significant relationship in nasopalatine foramen ( $p=0.005$; Table 2). With respect to age, the shapes of nasopalatine foramen, incisive foramen and the mid-level of NPC were not statistically significant $(p=0.560, p=0.187$, $p=0.576$, respectively). In the sagittal plane, the type of canal and the other categorical values were compared and a significant relationship was not detected between any parameters and the type of canal. 


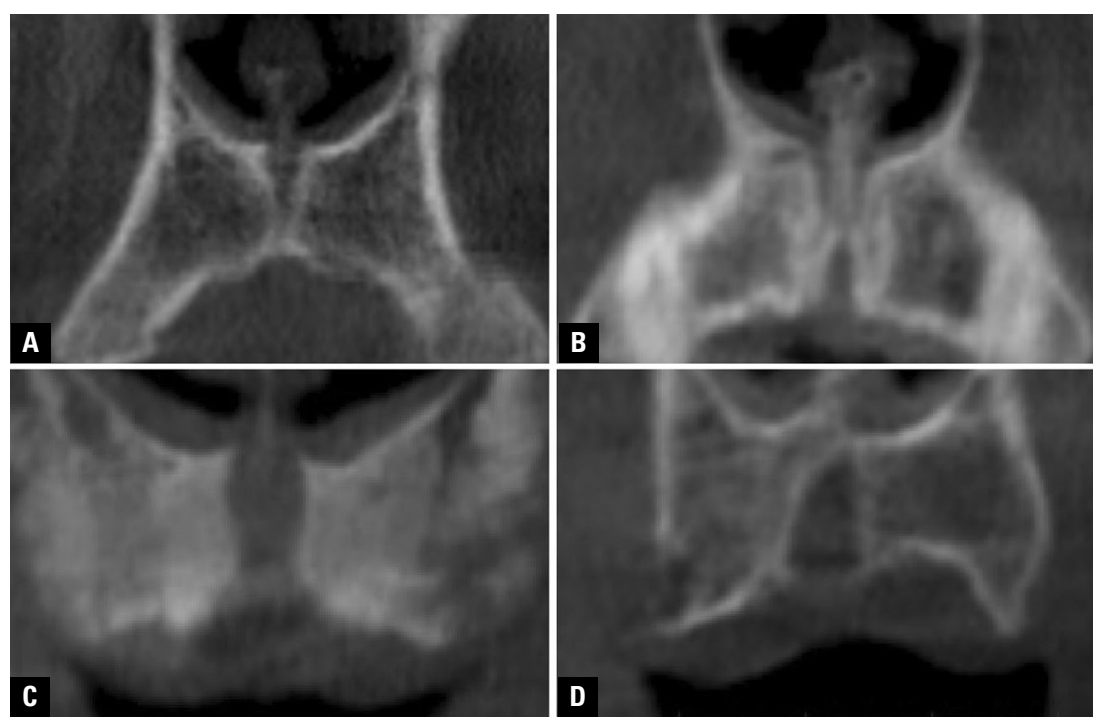

Figure 3. The external border of nasopalatine canal was classified in coronal plane; A. V-shaped; B. Y-shaped; C. U-shaped; D. Reverse V-shaped.
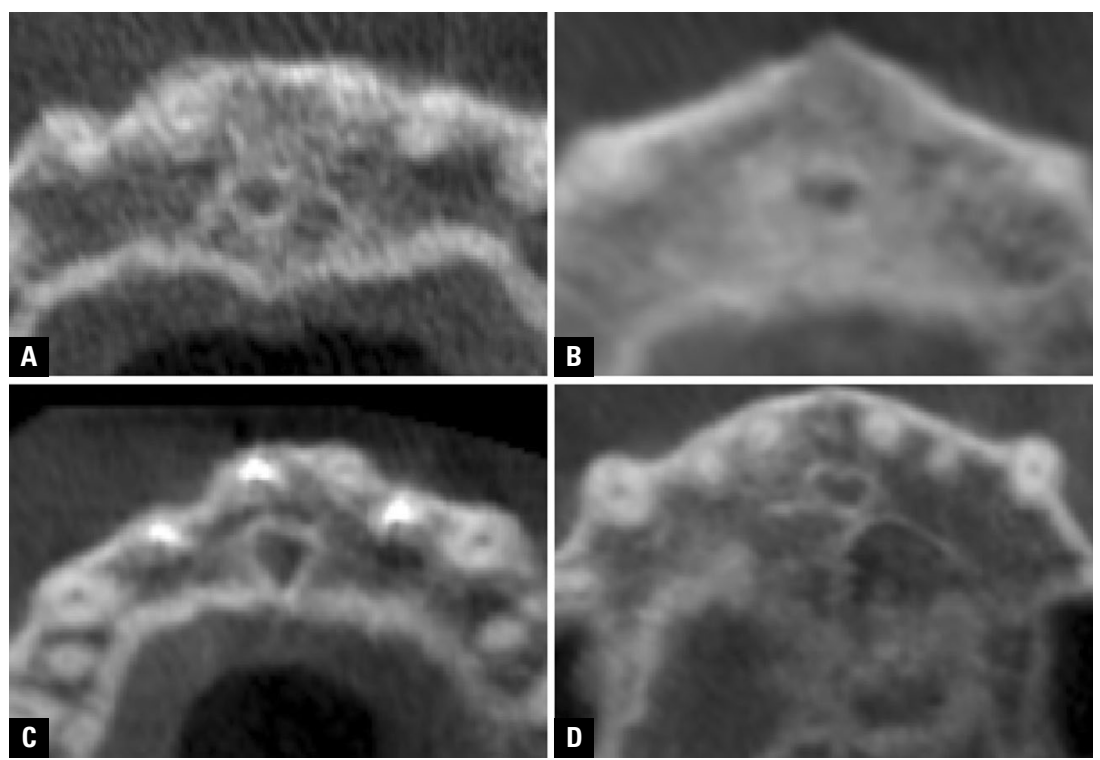

Figure 4. The shape of nasopalatine foramen, incisive foramen and nasopalatine canal at the mid-level was classified in axial plane; $\mathbf{A}$. Round-shaped; B. Oval-shaped; C. Triangle-shaped; D. Heart-shaped.
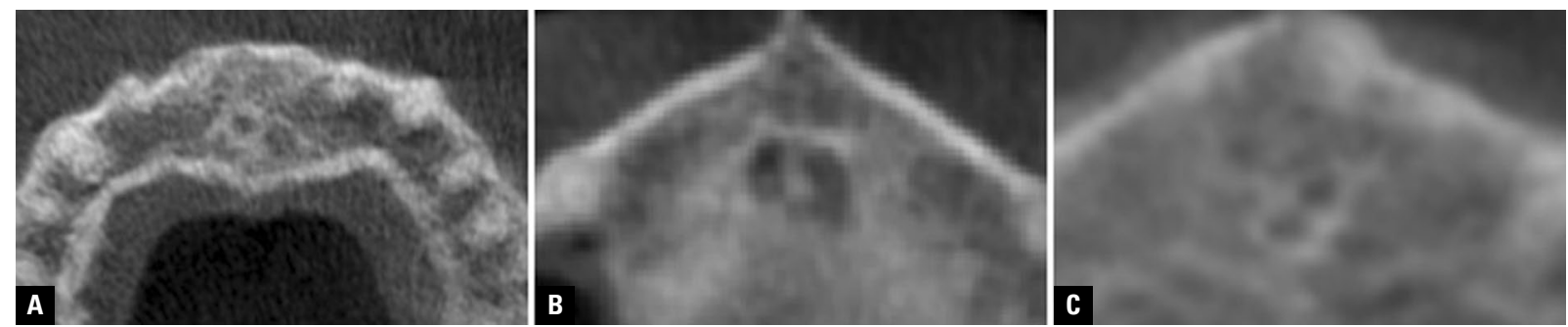

Figure 5. The numbers of nasopalatine foramen, incisive foramen and nasopalatine canal at the mid-level was classified in axial plane; $\mathbf{A}$. One opening; B. Two openings; C. Three openings. 

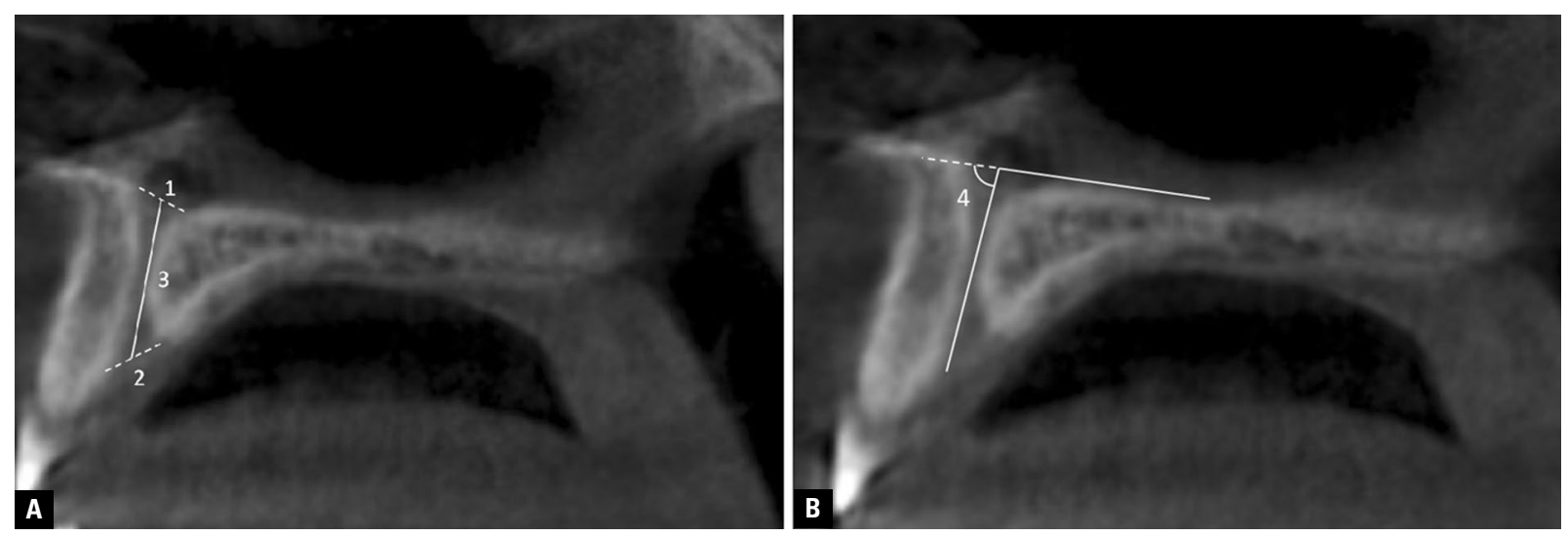

Figure 6. A, B. The measurement of diameters of nasopalatine and incisive foramen, and nasopalatine angle in sagittal plane; 1 - the diameter of nasopalatine foramen; 2 - the diameter of incisive foramen; 3 - the length of nasopalatine canal; 4 - nasopalatine canal angle.

Table 1. The shape of nasopalatine canal (NPC)

\begin{tabular}{|c|c|c|c|}
\hline Plane & & $\begin{array}{c}\text { The shape } \\
\text { of NPC }\end{array}$ & $\mathbf{N}(\%)$ \\
\hline \multirow[t]{7}{*}{ Sagittal } & & Cylindrical & $43(28.7)$ \\
\hline & & Hourglass & $40(26.7)$ \\
\hline & & Banana & $24(16.0)$ \\
\hline & & Cone & $22(14.7)$ \\
\hline & & Funnel & $20(13.3)$ \\
\hline & & Reverse cone & $1(0.7)$ \\
\hline & & Total & $150(100.0)$ \\
\hline \multirow[t]{9}{*}{ Coronal } & Shape of NPC & $\mathrm{Y}$ & $95(63.3 \%)$ \\
\hline & & Single canal & $54(36.0 \%)$ \\
\hline & & Double canal & $1(0.7 \%)$ \\
\hline & & Total & $150(100.0 \%)$ \\
\hline & External border of NPC & V & $66(44.0 \%)$ \\
\hline & & $Y$ & $43(28.7 \%)$ \\
\hline & & U & $40(26.7 \%)$ \\
\hline & & Reverse V & $1(0.7 \%)$ \\
\hline & & Total & $150(100.0 \%)$ \\
\hline \multirow[t]{14}{*}{ Axial } & Level of nasopalatine foramen & Round & $113(75.3 \%)$ \\
\hline & & Oval & $33(22.0 \%)$ \\
\hline & & Heart & $4(2.7 \%)$ \\
\hline & & Total & $150(100 \%)$ \\
\hline & Mid-level of NPC & Round & $78(52.0 \%)$ \\
\hline & & Oval & $16(10.7 \%)$ \\
\hline & & Heart & $55(36.7 \%)$ \\
\hline & & Triangle & $1(0.7 \%)$ \\
\hline & & Total & $150(100 \%)$ \\
\hline & Level of incisive foramen & Round & $94(62.7 \%)$ \\
\hline & & Oval & $24(16.0 \%)$ \\
\hline & & Heart & $31(20.7 \%)$ \\
\hline & & Triangle & $1(0.7 \%)$ \\
\hline & & Total & $150(100 \%)$ \\
\hline
\end{tabular}

Table 2. The distribution of the shape of nasopalatine foramen within genders in the axial planes

\begin{tabular}{lcccc}
\hline & Round & Oval & Heart & p \\
\hline Female & $65(86.7 \%)$ & $9(12 \%)$ & $1(1.3 \%)$ & \\
Male & $48(64 \%)$ & $24(32 \%)$ & $3(4 \%)$ & $0.005^{*}$ \\
Total & $113(75.3 \%)$ & $33(22 \%)$ & $4(2.7 \%)$ & \\
\hline
\end{tabular}

${ }^{*}$ Significance $(p \leq 0.05)$

\section{Measurements of NPC}

The number of openings at nasopalatine foramen and incisive foramen on the coronal and axial planes, also at mid-levels of NPC on the axial plane were shown in Table 3 and Figure 5. With respect to gender, only the number of openings at mid-level of NPC in the axial plane was statistically significant ( $p=0.024$; Table 4); however, there was no significant association between age and the number of these three openings.

The length of NPC, the diameters of nasopalatine and incisive foramen in the sagittal plane were shown in Table 5. Only the diameter of incisive foramen was found significantly larger in the males $(p=0.037$; Table 5), and there was no significant association between the age and these three parameters $(p=0.485$, $p=0.218, p=0.869$, respectively). It was detected in the sagittal plane that there was a statistically significant relationship between the type of the canal and the diameter of nasopalatine foramen $(p=0.005)$. The biggest nasopalatine foramen diameter was detected in hourglass-shaped NPC, followed by banana-shaped, cylindrical, cone- and funnel-shaped NPC. 
Table 3. The numbers of nasopalatine foramen, incisive foramen and nasopalatine canal (NPC) at the mid-level

\begin{tabular}{lcccc}
\hline Plane & Section level & One opening & Two openings & Three openings \\
\hline Coronal & Nasopalatine foramen & $54(36.0 \%)$ & $95(63.3 \%)$ & $1(0.7 \%)$ \\
& Incisive foramen & $149(99.3 \%)$ & $1(0.7 \%)$ & - \\
Axial & Nasopalatine foramen & $80(53 . \% 3)$ & $67(44.7 \%)$ & $3(2 \%)$ \\
& Mid-level of NPC & $145(96.7 \%)$ & $4(2.7 \%)$ & $1(0.7 \%)$ \\
& Incisive foramen & $132(88 \%)$ & $18(12 \%)$ & - \\
\hline
\end{tabular}

Table 4. The measured numeric values were compared by genders (female, $n=75$, male, $n=75$ )

\begin{tabular}{|c|c|c|c|c|}
\hline Plane & Parameter & Gender & Mean \pm SD & $\mathbf{P}$ \\
\hline \multirow[t]{4}{*}{ Coronal } & The number of opening at nasopalatine foramen & Female & $1.60 \pm 0.52$ & 0.248 \\
\hline & & Male & $1.69 \pm 0.46$ & \\
\hline & The number of opening at incisive foramen & Female & $1.01 \pm 0.12$ & 0.321 \\
\hline & & Male & $1.00 \pm 0.00$ & \\
\hline \multirow[t]{6}{*}{ Axial } & The number of opening at nasopalatine foramen & Female & $1.47 \pm 0.50$ & 1.000 \\
\hline & & Male & $1.47 \pm 0.50$ & \\
\hline & The number of opening at incisive foramen & Female & $1.17 \pm 0.42$ & 0.197 \\
\hline & & Male & $1.09 \pm 0.34$ & \\
\hline & The number of opening at mid-level of NPC & Female & $1.07 \pm 0.25$ & $0.024^{*}$ \\
\hline & & Male & $1.00 \pm 0.00$ & \\
\hline \multirow[t]{8}{*}{ Sagittal } & The diameter of nasopalatine foramen [mm] & Female & $4.25 \pm 1.15$ & 0.164 \\
\hline & & Male & $4.01 \pm 0.99$ & \\
\hline & The diameter of incisive foramen [mm] & Female & $6.71 \pm 1.50$ & $0.037^{*}$ \\
\hline & & Male & $6.23 \pm 1.28$ & \\
\hline & The length of NPC [mm] & Female & $12.96 \pm 2.57$ & 0.052 \\
\hline & & Male & $12.16 \pm 2.45$ & \\
\hline & NPC angle [ $\left.{ }^{\circ}\right]$ & Female & $74.02 \pm 7.77$ & 0.675 \\
\hline & & Male & $74.55 \pm 7.72$ & \\
\hline
\end{tabular}

*Significance ( $\mathrm{p} \leq 0.05)$; NPC — nasopalatine canal; SD — standard deviation

Table 5. The evaluation of nasopalatine canal (NPC) in the sagittal plane (female, $n=75$, male, $n=75$ )

\begin{tabular}{|c|c|c|c|}
\hline Gender & Mean \pm SD & Minimum-maximum & $\mathbf{P}$ \\
\hline \multicolumn{4}{|c|}{ The diameter of nasopalatine foramen [mm]: } \\
\hline Female & $4.01 \pm 0.99$ & $2.00-6.45$ & 0.164 \\
\hline Male & $4.25 \pm 1.15$ & $1.60-6.71$ & \\
\hline Total & $4.13 \pm 1.08$ & $1.60-6.71$ & \\
\hline \multicolumn{4}{|c|}{ The diameter of incisive foramen [mm]: } \\
\hline Female & $6.23 \pm 1.28$ & $3.42-8.99$ & $0.037^{*}$ \\
\hline Male & $6.71 \pm 1.50$ & $3.22-10.73$ & \\
\hline Total & $6.47 \pm 1.41$ & $3.22-10.73$ & \\
\hline \multicolumn{4}{|c|}{ The length of NPC [mm]: } \\
\hline Female & $12.16 \pm 2.45$ & $6.66-17.91$ & 0.052 \\
\hline Male & $12.96 \pm 2.57$ & $7.09-19.76$ & \\
\hline Total & $12.56 \pm 2.53$ & $6.66-19.76$ & \\
\hline
\end{tabular}

${ }^{*}$ Significance $(p \leq 0.05) ; S D$ - standard deviation 
In the sagittal plane, the NPC angle was measured as $74.28^{\circ} \pm 7.72^{\circ}$. No statistically significant difference was detected between the genders $(p=0.675 ;$ Table 4). There was a weak negative correlation between the age and the NPC angle ( $p=0.012, r=0.204)$. However, no statistically significant correlation was observed between the angle of NPC and the length of NPC $(p=0.162)$.

\section{DISCUSSION}

Even if traditional imaging methods (intra-oral radiography and panoramic imaging) are suitable methods because of low radiation doses, they are not considered safe in evaluation of the region before the surgical intervention as they allow for two-dimensional evaluation [7, 20, 38]. Three-dimensional imaging can be carried out via spiral or multiplanar $\mathrm{CT}$; however, this method is not preferred because of high radiation dose and cost. CBCT has been recently accepted as the most ideal imaging method for the dentomaxillofacial diagnosis due to its cheaper cost and low radiation dose $[2,3,20]$.

Implant procedure is often preferred in tooth loss treatment in the anterior region because of its aesthetic and functional advantages [36]. Placement of implants into the NPC may lead to many complications such as bleeding during the operation, postoperative short-term sensory disorder, non-osseointegration of the implant and the formation of nasopalatine canal cyst $[9,25,26,30,35]$. Therefore, a detailed imaging of the relevant region is very important to prepare a suitable surgical intervention programme.

Although there are many studies indicating the pathologies related to NPC in the literature $[4,5,8$, $9,12,14,17,18,22,23,27,29,30,31]$, the studies concerning the anatomy of NPC evaluated via CBCT are limited [1, 11, 13, 16, 19, 21, 37].

\section{The shape of NPC}

NPC in the sagittal plane. NPC was studied on dry skulls and CT images and classified according to their shapes in different studies. Liang et al. [22] classified NPC in two groups on 163 dry skulls and stated that 87 of them were cylindrical and 75 of them were cone-shaped. Mardinger et al. [23] studied CT images of 207 cases and detected that $50.7 \%$ of NPC was cylindrical, $30.9 \%$ of them was funnel-shaped, $14.5 \%$ of them was hourglass-shaped and the lowest percentage of it was banana-shaped. Gönül et al. [17] evaluated NPC in four groups on CT images of
100 cases and stated that $48 \%$ of those cases were cylindrical, $20 \%$ of them were hourglass-shaped, $20 \%$ of them were banana-shaped and $12 \%$ of them were funnel-shaped. Güncü et al. [18] evaluated 417 male and 516 female cases on CT images and detected that NPC was cylindrical most frequently, followed by the cone-, hourglass- and least frequently banana-shaped. Etoz and Sisman [13] studied CT images of 500 cases; they found that $38.8 \%$ of NPCs were hourglass-shaped, $27.3 \%$ funnel-shaped, $14.7 \%$ banana-shaped, 9.2\% cone-shaped, $8.6 \%$ cylindrical and $1.4 \%$ were tree branch-shaped. Fernández-Alonso et al. [16] detected NPC on CT images of 230 cases, as $48.2 \%$ cylindrical, $30.9 \%$ hourglass-, $20.5 \%$ funnel- and $0.4 \%$ banana-shaped. Hakbilen and Magat [19] studied CBCT images of 619 cases; they found that in $26.17 \%$ NPC was conical, in $24.71 \%$ hourglass-, in $16.80 \%$ cylindrical, in $15.83 \%$ funnel- and in $11.14 \%$ banana-shaped. In the present study, NPC was classified in six groups: cylindrical, hourglass-, banana-, cone-, funnel- and reverse cone-shaped. Most of the studies in the literature, together with this study, have identified cylindrical NPC as the most common type of nasopalatine canal [16-18, 23]. Etoz and Sisman [13] have identified hourglass-shaped NCP as the most common type. Hakbilen and Magat [19] have identified conical NCP as the most common type.

NPC in the coronal plane. In some studies, NPC was classified on $\mathrm{CT}$ images in the coronal plane. Bornstein et al. [8] classified 100 NPC in three groups. It was detected that $45 \%$ of the cases were single canals, $40 \%$ of them were Y-shaped and $15 \%$ of them were double canals. Gönül et al. [17] classified 100 NPC in three groups. It was determined that $58 \%$ of the cases were single canals, $19 \%$ of them were Y-shaped and $13 \%$ of them were parallel canals. Fernández-Alonso et al. [16] evaluated 230 cases and classified NPC in three groups. They found that $45.9 \%$ were $Y$-shaped, $41.1 \%$ were single canals and 10.3\% parallel canals. Jornet et al. [21] classified 122 NPC in three groups. They found that $52.45 \%$ of the cases were $Y$-shaped, $39.34 \%$ single canals and $8.19 \%$ double canals. In these studies, NPC is classified by whether or not there is bone division. In our study, the shape of NPC was classified in three groups: $63.3 \%$ were $Y$-shaped, $36.0 \%$ were single canals, $0.7 \%$ were double canals and external border of NPC was classified as U-, Y-, V- and reverse V-shaped in order to compare upper, middle and lower widths of NPC 
Table 6. Comparison of measurements in the axial plane with the literature

\begin{tabular}{|c|c|c|c|c|c|c|}
\hline \multirow[t]{2}{*}{ Study } & \multicolumn{2}{|c|}{ Level of nasopalatine foramen } & \multicolumn{2}{|c|}{ Mid-level of NPC } & \multicolumn{2}{|c|}{ Level of incisive foramen } \\
\hline & Number & Shape & Number & Shape & Number & Shape \\
\hline Etoz and Sisman [13] & $1(44.3 \%)$ & - & - & - & - & - \\
\hline Song et al. [33] & $2(100 \%)$ & - & $1(42.9 \%)$ & - & $1(100 \%)$ & - \\
\hline Liang et al. [22] & $1(44 \%)$ & - & - & - & - & - \\
\hline Thakur et al. [37] & $2(81 \%)$ & - & - & - & - & - \\
\hline Acar and Kamburoğlu [1] & - & Round (44\%) & - & - & - & - \\
\hline Gönül et al. [17] & $2(57 \%)$ & Round (52\%) & - & - & - & - \\
\hline Fernández-Alonso et al. [16] & 2 & - & - & - & 1 & - \\
\hline Present study & $1(53.3 \%)$ & Round (75.3\%) & $1(96.7 \%)$ & Round (52\%) & $1(88 \%)$ & Round (62.7\%) \\
\hline
\end{tabular}

NPC - nasopalatine canal

with each other $(26.7 \% \mathrm{U}-, 28.7 \% \mathrm{Y}-, 44.0 \% \mathrm{~V}$ - and $0.7 \%$ reverse $\mathrm{V}$-shaped).

NPC in the axial plane. In some studies, NPC was classified according to the number and shape on CT images in the axial plane. Etoz and Sisman [13] classified nasopalatine foramens in four groups on the axial section: 1 (44.3\%) opening, 2 (38.4\%) openings, 3 (14.7\%) openings and 4 (2.7\%) openings. However, they did not give any information about the number of incisive foramens. Song et al. [33] stated that there are always 2 nasopalatine foramina and incisive foramen is always single. They classified NPC in four groups on the basis of the axial section through its middle part: $42.9 \%-1$ channel, $23.2 \%-2$ channels, $25 \%-3$ channels, and $8.9 \%-$ 4 channels. Liang et al. [22] reported a classification of nasopalatine foramens: $44 \%$ cases with 1 opening, $39 \%$ with 2 openings, and $17 \%$ with 3 or 4 openings. Thakur et al. [37] noticed it as $81 \%-2$ openings, $13 \%-3$ openings, $4 \%-1$ opening, and $2 \%-$ 4 openings. Gönül et al. [17] established nasopalatine foramen as, $57 \%-2$ openings, $21 \%-3$ openings, $13 \%-1$ opening, and $8 \%-4$ openings. Acar and Kamburoğlu [1] found NPC as round in $44 \%$, heart-shaped in 30\%, and oval-shaped in $26 \%$. Gönül et al. [17] reported it as round in $52 \%$, heart-shaped in $25 \%$, oval in $15 \%$ and triangle-shaped in $6 \%$. Fernández-Alonso et al. [16] evaluated nasopalatine foramen and incisive foramen together and they detected that most frequently (50.9\%) there are one incisive foramen and two nasopalatine foramina and that second most frequent configuration (25.4\%) is one incisive foramen and one nasopalatine foramen. In the present study, the classification was done in four groups in the axial planes passing through the upper, middle and lower parts of NPC: round-, oval-, heart- and triangle-shaped (Table 6). The limited parameters were evaluated in the other studies done in the axial plane, and all the parameters were evaluated in the present study. It was seen in every three axial planes that the round-shaped group is more numerous than the others. One nasopalatine foramen, one incisive foramen and one channel at mid-level of NPC were seen more frequently than other configurations.

\section{Measurement}

The comparison of numeric parameters (diameter of the nasopalatine foramen, diameter of the incisive foramen, NPC length and NPC angle) in the sagittal plane with the literature is given in Table 7. Hakbilen and Magat [19], Jornet et al. [21], Bornstein et al. [8], and Gönül et al. [17] detected a statistically significant difference in NPC length between genders. In the present study, a statistically significant difference was determined in diameter of the incisive foramen between genders $(p=0.037)$. Diameter of incisive foramen is thought to be less than $6 \mathrm{~mm}$ in general, and it is accepted that it may be pathologic if it exceeds $10 \mathrm{~mm}$ [26]. The mean of the diameter of incisive foramen was found $6.47 \pm 1.41$ in the present study.

It has been confirmed in the present study that there is not any significant difference in NPC angle between genders, as in the other studies $[1,8,13$, $16,17,19,21,37]$ (Table 7). The numeric variables were correlated with age and only a weak significant negative correlation was observed between age and NPC angle ( $p=0.012, r=0.204)$. According the result; it is thought that NPC angle is decreased due to resorption of the palate as the age progresses. The 


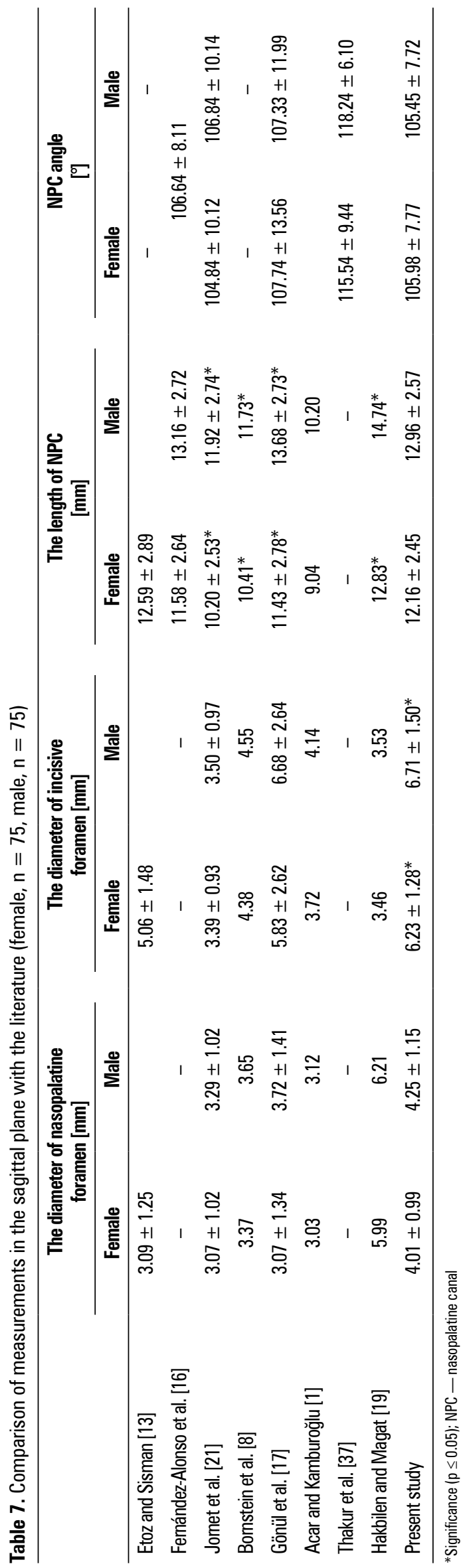

orientation and the angle of NPC should be assessed for the purpose of angulation and placement of the dental implants in this area.

\section{CONCLUSIONS}

As a result of measurements made on CBCT images, it has been found that there are many anatomic variations of NPC. The morphological properties and variations of NPC should be considered with a correct radiological evaluation so as to prevent the complications and improper applications in local anaesthesia, maxillary surgery and implant application. Especially dentists, otolaryngologist and plastic surgeons need to know the anatomy and variations of NPC.

\section{Acknowledgements}

The authors are grateful to Associate Professor Dr. Seval KUL, Department of Biostatistics, School of Medicine, Gaziantep University for the support.

\section{REFERENCES}

1. Acar B, Kamburoğlu K. Morphological and volumetric evaluation of the nasopalatinal canal in a Turkish population using cone-beam computed tomography. Surg Radiol Anat. 2015; 37(3): 259-265, doi: 10.1007/s00276-014-1348-9, indexed in Pubmed: 25038838.

2. Arai $Y$, Hashimoto $K$, Iwai $K$, et al. Fundamental efficiency of limited cone-beam X-ray CT (3DX multi image micro CT) for practical use. Shika Hoshasen. 2000; 40(2): 145-154.

3. Arai Y, Honda K, Iwai K, et al. Practical model "3DX" of limited cone-beam X-ray CT for dental use. International Congress Series. 2001; 1230: 713-718, doi: 10.1016/s05315131(01)00119-4.

4. Artzi Z, Nemcovsky CE, Bitlitum I, et al. Displacement of the incisive foramen in conjunction with implant placement in the anterior maxilla without jeopardizing vitality of nasopalatine nerve and vessels: a novel surgical approach. Clin Oral Implants Res. 2000; 11(5): 505-510, indexed in Pubmed: 11168243.

5. Asaumi R, Kawai T, Sato I, et al. Three-dimensional observations of the incisive canal and the surrounding bone using cone-beam computed tomography. Oral Radiology. 2010; 26(1): 20-28, doi: 10.1007/s11282-010-0039-4.

6. Bahşi I, Orhan M, Kervancioglu P. A sample of morphological eponym confusion: foramina of Stenson/Stensen. Surg Radiol Anat. 2017; 39(8): 935-936, doi: 10.1007/s00276-017-1835-x, indexed in Pubmed: 28247083.

7. Bernardes RA, de Moraes IG, Húngaro Duarte MA, et al. Use of cone-beam volumetric tomography in the diagnosis of root fractures. Oral Surg Oral Med Oral Pathol Oral Radiol Endod. 2009; 108(2): 270-277, doi: 10.1016/j.tripleo.2009.01.017, indexed in Pubmed: 19272806.

8. Bornstein MM, Balsiger R, Sendi $P$, et al. Morphology of the nasopalatine canal and dental implant surgery: a radiographic analysis of 100 consecutive patients using limited cone-beam computed tomography. Clin Oral Implants Res. 2011; 22(3): 295-301, doi: 10.1111/j.1600-0501.2010.02010.x, indexed in Pubmed: 21039896.

9. Casado PL, Donner M, Pascarelli B, et al. Immediate dental implant failure associated with nasopalatine duct cyst. Implant Dent. 2008; 17(2): 169-175, doi: 10.1097/ID. 0b013e3181776c52, indexed in Pubmed: 18545048. 
10. Cavallaro J, Tsuji S, Chiu TS, et al. Management of the nasopalatine canal and foramen associated with dental implant therapy. Compend Contin Educ Dent. 2016; 38(6): 367-372; quiz 374, indexed in Pubmed: 28570082.

11. Chatriyanuyoke $P, \operatorname{Lu} \mathrm{Cl}$, Suzuki $Y$, et al. Nasopalatine canal position relative to the maxillary central incisors: a cone beam computed tomography assessment. J Oral Implantol. 2012; 38(6): 713-717, doi: 10.1563/AAID-JOI-D-10-00106, indexed in Pubmed: 20932126.

12. Cicciù $M$, Grossi GB, Borgonovo $A$, et al. Rare bilateral nasopalatine duct cysts: a case report. Open Dent J. 2010; 4: 8-12, doi: 10.2174/1874210601004010008, indexed in Pubmed: 20386720.

13. Etoz M, Sisman Y. Evaluation of the nasopalatine canal and variations with cone-beam computed tomography. Surg Radiol Anat. 2014; 36(8): 805-812, doi: 10.1007/s00276-0141259-9, indexed in Pubmed: 24488202.

14. Faitaroni LA, Bueno MR, Carvalhosa AA, et al. Differential diagnosis of apical periodontitis and nasopalatine duct cyst. J Endod. 2011; 37(3): 403-410, doi: 10.1016/j.joen.2010.11.022, indexed in Pubmed: 21329830.

15. FCAT. Terminologica Anatomica. Federative Committee on Anatomical Terminology. Stuggart: Thieme. 1998.

16. Fernández-Alonso A, Suárez-Quintanilla JA, Muinelo-Lorenzo J, et al. Three-dimensional study of nasopalatine canal morphology: a descriptive retrospective analysis using conebeam computed tomography. Surg Radiol Anat. 2014; 36(9): 895-905, doi: 10.1007/s00276-014-1297-3, indexed in Pubmed: 24752396

17. Gönül $Y$, Bucak $A$, Atalay $Y$, et al. MDCT evaluation of nasopalatine canal morphometry and variations: An analysis of 100 patients. Diagn Interv Imaging. 2016; 97(11): 1165-1172, doi: 10.1016/j.diii.2015.11.012, indexed in Pubmed: 26797526.

18. Güncü GN, Yıldırım YD, Yılmaz HG, et al. Is there a gender difference in anatomic features of incisive canal and maxillary environmental bone? Clin Oral Implants Res. 2013; 24(9): 1023-1026, doi: 10.1111/j.1600-0501.2012.02493.x, indexed in Pubmed: 22587805.

19. Hakbilen S, Magat G. Evaluation of anatomical and morphological characteristics of the nasopalatine canal in a Turkish population by cone beam computed tomography. Folia Morphol. 2018; 77(3): 527-535, doi: 10.5603/FM.a2018.0013, indexed in Pubmed: 29399754.

20. Harris D, Buser D, Dula K, et al. European Association for Osseointegration. E.A.O. guidelines fo the use of diagnostic imaging in implant dentistry. A consensus workshop organized by the European Association for Osseointegration in Trinity College Dublin. Clin Oral Implants Res. 2002; 13(5): 566-570, doi: 10.1111/j.1600-0501.2012.02441.x, indexed in Pubmed: 12674118.

21. Jornet PL, Boix P, Sanchez Perez A, et al. Morphological characterization of the anterior palatine region using cone beam computed tomography. Clin Implant Dent Relat Res. 2015; 17 Suppl 2: e459-e464, doi: 10.1111/cid.12271, indexed in Pubmed: 25263847.

22. Liang $X$, Jacobs $R$, Martens W, et al. Macro- and micro-anatomical, histological and computed tomography scan characterization of the nasopalatine canal. J Clin Periodontol. 2009; 36(7): 598-603, doi: 10.1111/j.1600-051X.2009.01429.x, indexed in Pubmed: 19538333.

23. Mardinger O, Namani-Sadan N, Chaushu G, et al. Morphologic changes of the nasopalatine canal related to dental implantation: a radiologic study in different degrees of absorbed maxillae. J Periodontol. 2008; 79(9): 1659-1662, doi: 10.1902/ jop.2008.080043, indexed in Pubmed: 18771366.
24. McCrea SJJ. Aberrations causing neurovascular damage in the anterior maxilla during dental implant placement. Case Rep Dent. 2017; 2017: 5969643, doi: 10.1155/2017/5969643, indexed in Pubmed: 28785491.

25. McCrea SJ. Nasopalatine duct cyst, a delayed complication to successful dental implant placement: diagnosis and surgical management. J Oral Implantol. 2012 [Epub ahead of print]; 40(2)-195, doi: 10.1563/AAID-JOI-D-12-00011.1, indexed in Pubmed: 22409652.

26. Mraiwa N, Jacobs R, Van Cleynenbreugel J, et al. The nasopalatine canal revisited using 2D and 3D CT imaging. Dentomaxillofac Radiol. 2004; 33(6): 396-402, doi: 10.1259/ $\mathrm{dmfr} / 53801969$, indexed in Pubmed: 15665234.

27. Nelson BL, Linfesty RL. Nasopalatine duct cyst. Head Neck Pathol. 2010; 4(2): 121-122, doi: 10.1007/s12105-010-0169-3, indexed in Pubmed: 20512635.

28. Neves FS, Oliveira LK, Ramos Mariz AC, et al. Rare anatomical variation related to the nasopalatine canal. Surg Radiol Anat. 2013; 35(9): 853-855, doi: 10.1007/s00276-013-1089-1, indexed in Pubmed: 23455363.

29. Oliveira-Santos C, Rubira-Bullen IRF, Monteiro SAC, et al. Neurovascular anatomical variations in the anterior palate observed on CBCT images. Clin Oral Implants Res. 2013; 24(9): 1044-1048, doi: 10.1111/j.1600-0501.2012.02497.x, indexed in Pubmed: 22587228

30. Peñarrocha D, Candel E, Guirado JL, et al. Implants placed in the nasopalatine canal to rehabilitate severely atrophic maxillae: a retrospective study with long follow-up. J Oral Implantol. 2014; 40(6): 699-706, doi: 10.1563/AAID-JOI-D-12-00145, indexed in Pubmed: 23397941.

31. Peñarrocha $M$, Carrillo $C$, Uribe $R$, et al. The nasopalatine canal as an anatomic buttress for implant placement in the severely atrophic maxilla: a pilot study. Int J Oral Maxillofac Implants. 2009; 24(5): 936-942, indexed in Pubmed: 19865635.

32. Sekerci AE, Buyuk SK, Cantekin K. Cone-beam computed tomographic analysis of the morphological characterization of the nasopalatine canal in a pediatric population. Surg Radiol Anat. 2014; 36(9): 925-932, doi: 10.1007/s00276-014-1271-0, indexed in Pubmed: 24590491.

33. Song WC, Jo DI, Lee JY, et al. Microanatomy of the incisive canal using three-dimensional reconstruction of microCT images: an ex vivo study. Oral Surg Oral Med Oral Pathol Oral Radiol Endod. 2009; 108(4): 583-590, doi: 10.1016/j. tripleo.2009.06.036, indexed in Pubmed: 19778745.

34. Standring S. Gray's anatomy: the anatomical basis of clinical practice. 41. Edition ed: Elsevier Health Sciences. 2016.

35. Takeshita K, Funaki K, Jimbo R, et al. Nasopalatine duct cyst developed in association with dental implant treatment: A case report and histopathological observation. J Oral Maxillofac Pathol. 2013; 17(2): 319, doi: 10.4103/0973-029X.119761, indexed in Pubmed: 24250105.

36. Teughels W, Merheb J, Quirynen M. Critical horizontal dimensions of interproximal and buccal bone around implants for optimal aesthetic outcomes: a systematic review. Clin Oral Implants Res. 2009; 20 Suppl 4: 134-145, doi: 10.1111/j.16000501.2009.01782.x, indexed in Pubmed: 19663960.

37. Thakur AR, Burde K, Guttal K, et al. Anatomy and morphology of the nasopalatine canal using cone-beam computed tomography. Imaging Sci Dent. 2013; 43(4): 273-281, doi: 10.5624/ isd.2013.43.4.273, indexed in Pubmed: 24380067.

38. Youssefzadeh S, Gahleitner A, Dorffner R, et al. Dental vertical root fractures: value of CT in detection. Radiology. 1999; 210(2): 545-549, doi: 10.1148/radiology.210.2.r99ja20545, indexed in Pubmed: 10207442. 